\title{
Erratum to: Postoperative cognitive dysfunction after noncardiac surgery: effects of metabolic syndrome
}

\author{
Judith A. Hudetz $\cdot$ Kathleen M. Patterson • \\ Oludara Amole $\cdot$ Aaron V. Riley $\cdot$ Paul S. Pagel
}

Published online: 14 September 2011

(C) Japanese Society of Anesthesiologists 2011

\section{Erratum to: J Anesth (2011) 25:337-344 \\ DOI 10.1007/s00540-011-1137-0}

The original version of this article contained errors, unfortunately. The incidence of postoperative cognitive dysfunction in patients with metabolic syndrome was $17 / 30$ (not 13/30; this is an error); therefore, the last sentence of the Results section (in the abstract and the main body of the article) should read "The prevalence rate of POCD was different in the studied groups (17/30 and 8/30 in patients with versus without metabolic syndrome; $P<0.02)$."
The following erratum was published earlier:

The original version of this article contained errors, unfortunately. The column heads and footnotes for Tables 3 and 4 should refer to 1-month, not 1-week, testing. Therefore, in both tables the heads should read "1 month" instead of " 1 week" and "p1M" instead of "p1W". The footnotes should read "p1M between-group significance after 1 month (repeated-measures analysis of variance)" instead of "p1W between-group significance after 1 week (repeated-measures analysis of variance)".

The online version of the original article can be found under doi:10.1007/s00540-011-1137-0.

J. A. Hudetz $(\bowtie) \cdot$ O. Amole P. S. Pagel

Division of Anesthesiology, Clement J. Zablocki Veterans

Administration Medical Center, 5000 W. National Avenue,

Milwaukee, WI 53295, USA

e-mail: judith.hudetz@va.gov

J. A. Hudetz · K. M. Patterson · P. S. Pagel

Medical College of Wisconsin, 8701 Watertown Plank Road,

Milwaukee, WI 53226, USA

K. M. Patterson

Division of Acute Mental Health, Clement J. Zablocki Veterans

Administration Medical Center, 5000 W. National Avenue,

Milwaukee, WI 53295, USA

\section{A. V. Riley}

Division of Psychiatry, Clement J. Zablocki Veterans

Administration Medical Center, 5000 W. National Avenue,

Milwaukee, WI 53295, USA 